\title{
Editorial \\ Epitope spreading in animal models: array of hope in rheumatoid arthritis and multiple sclerosis
}

\author{
Karin Lundberg and Patrick J Venables
}

Kennedy Institute of Rheumatology, Imperial College London, 65 Aspenlea Road, London W6 8LH, UK

Corresponding author: Karin Lundberg, k.lundberg@imperial.ac.uk

See related research article by Kidd et al., http://arthritis-research.com/content/10/5/R119

Published: 25 November 2008

This article is online at http://arthritis-research.com/content/10/6/122

(c) 2008 BioMed Central Ltd

Arthritis Research \& Therapy 2008, 10:122 (doi:10.1186/ar2544)

\begin{abstract}
The paradigm for pathogenic autoimmunity is the generation of high-titre, affinity-matured autoantibodies to a restricted family of autoantigens, in the appropriate genetic context. Genetic determinants of autoimmunity are largely found within the major histocompatibility complex (MHC) and the 'genotype to serotype to phenotype' concept is supported in a number of autoimmune diseases, where both genotype and serotype are well established. The serotype is autoantigen-driven, with evidence of epitope spreading as the disease evolves from asymptomatic to pathogenic autoimmunity. In rheumatoid arthritis and multiple sclerosis, where the autoantigens are poorly characterised, the use of an array in animal models may produce a hint of what happens in human disease. A more complete picture will be obtained from animals transgenic for human MHC, immunised with known human autoantigens.
\end{abstract}

\section{Epitope spreading in animal models of rheumatoid arthritis and multiple sclerosis}

In a recent issue, Kidd and colleagues [1] have attempted an analysis of epitope spreading in murine collagen-induced arthritis and experimental autoimmune encephalomyelitis as models of rheumatoid arthritis (RA) and multiple sclerosis (MS). This is a courageous undertaking, because the major histocompatibility complex (MHC) differs between mouse and man and, therefore, any MHC-dependent autoimmune response may also differ. In the human form of both diseases, the autoantigens remain poorly characterised. In RA, citrullinated antigens are likely to be the major targets of the autoimmune response. This conclusion is supported by the high specificity of antibodies to cyclic citrullinated peptides (CCPs) both in diagnosing and predicting disease. The specific target antigens include citrullinated fibrinogen, citrullinated vimentin, citrullinated collagen type II (reviewed in [2]) and, more recently, citrullinated $\alpha$-enolase [3]. In $\alpha$ enolase, there is evidence of an independent immune response to multiple citrullinated epitopes within the molecule [3]. In MS, a number of candidate autoantigens are associated with myelin, though the predictive and diagnostic value of their associated autoantibodies is disappointing [4]. In both murine models, the primary autoantigen is the protein used to induce the disease. However, in RA, it is clear that native collagen is not 'the' autoantigen and the intense antibody response to proteolipid protein, seen in experimental autoimmune encephalomyelitis, is not present in MS.

Kidd and colleagues attempt a non-prejudicial approach to dealing with the range of autoantigens that might be pathogenic in RA and MS by array technology. They used 253 antigens for their synovial array and 406 for their myelin array. This, of course, is a tiny fraction of the proteome and their choice had to be restricted to some of the antigens described as candidates in the previous literature. In spite of these limitations, they showed that antibodies to other candidate antigens, including citrullinated peptides, developed during the course of both diseases. They interpreted this as being due to intermolecular epitope spreading arising from the expression of citrullinated proteins as neoantigens in inflamed tissue. Some support for this hypothesis was provided by anti-citrulline immunoblotting, which demonstrated an increase of citrullinated proteins in both inflamed synovium and brain tissue. Other interpretations, however, include the possibility that antibodies to citrullinated proteins arise as a result of polyclonal activation as part of the 'natural antibody' response to adjuvant. Kidd and colleagues did not use an adjuvant-only immunised group of mice as controls, nor did they distinguish $\lg$ M from $\lg G$ antibodies. A further control not examined was the testing of the $\mathrm{Cll}$ immunised mice on the myelin array or vice versa. A controversial finding in this study was the demonstration of citrulline specificity for the antibodies to citrullinated peptides. This has also been 
reported in one previous study of collagen-induced arthritis [5], though other studies have found equal binding to both citrullinated and arginine-containing control peptides [6]. In $\mathrm{RA}$, the anti-CCP response reflects the genotype-serotypephenotype model, with antibodies to citrullinated proteins being closely correlated with the presence of the $\mathrm{MHC}$ shared epitope [7] and it has been argued that the shared epitope is required to present citrulline containing peptides to responder $\mathrm{T}$ cells [8]. Therefore, the most convincing murine model of RA is that of the recently reported DR4-IE transgenic mouse immunised with citrullinated fibrinogen [9].

The impressive, though often uncontrolled, array of data that arises from this sort of work is often regarded as hypothesisgenerating rather than hypothesis-testing. The study from Kidd and colleagues [1] falls in the former group, in that it provides more questions than answers. In the case of RA, some of the answers are already partially addressed by the recent reports of new disease-specific autoantibodies. In MS, the B cell autoantigens remain poorly characterised. Nevertheless, the authors have presented an exciting new model to provide some of the answers in the future. Now that we know more about the citrullinated antigens associated with the anti-CCP response and the requirement for specific $\mathrm{MHC}$ alleles, the use of transgenic animals could go a long way to analyse the autoimmune response in RA. In MS, where the autoimmune response appears to be less $\mathrm{MHC}$-restricted, better definition of the human autoantigens is required for further progress.

\section{Competing interests}

The authors reference their own work [3] in this editorial. Reference 3 concerns the immunodominant epitope of citrullinated alpha-enolase, denoted CEP-1. The sequence of the CEP-1 peptide is the subject of an international patent application, number WO0890360, published on 31st July 2008. The authors of this editorial, KL and PJV, are named as inventors on this patent application.

\section{References}

1. Kidd BA, Ho PP, Sharpe O, Zhao X, Tomooka BH, Kanter JL, Steinman L, Robinson WH: Epitope spreading to citrullinated antigens in mouse models of autoimmune arthritis and demyelination. Arthritis Res Ther 2008, 10:R119.

2. Kinloch A, Lundberg K, Venables P: The pathogenic role of antibodies to citrullinated proteins in rheumatoid arthritis. Expert Rev Clin Immunol 2006, 2:365-375.

3. Lundberg K, Kinloch A, Fisher BA, Wegner N, Wait R, Charles P, Mikuls TR, Venables PJ: Antibodies to citrullinated alphaenolase peptide 1 are specific for rheumatoid arthritis and cross-react with bacterial enolase. Arthritis Rheum 2008, 58: 3009-3019.

4. Wang $H$, Munger KL, Reindl M, O'reilly EJ, Levin LI, Berger T, Ascherio A: Myelin oligodendrocyte glycoprotein antibodies and multiple sclerosis in healthy young adults. Neurology 2008, 71:1142-1146.

5. Kuhn KA, Kulik L, Tomooka B, Braschler KJ, Arend WP, Robinson $\mathrm{WH}$, Holers VM: Antibodies against citrullinated proteins enhance tissue injury in experimental autoimmune arthritis. $J$ Clin Invest 2006, 116:961-973.

6. Vossenaar ER, Van Boekel MA, Van Venrooij WJ, Lopez-Hoyoz M, Merino J, Merino R, Joosten LA: Absence of citrulline-specific autoantibodies in animal models of autoimmunity. Arthritis Rheum 2004, 50:2370-2372.
7. Klareskog L, Ronnelid J, Lundberg K, Padyukov L, Alfredsson L: Immunity to citrullinated proteins in rheumatoid arthritis. Annu Rev Immunol 2008, 26:651-675.

8. Hill JA, Southwood S, Sette A, Jevnikar AM, Bell DA, Cairns E: Cutting Edge: The conversion of arginine to citrulline allows for a high-affinity peptide interaction with the rheumatoid arthritis-associated HLA-DRB1*0401 MHC Class II molecule. $\mathrm{J}$ Immuno/ 2003, 171:538-541.

9. Hill JA, Bell DA, Brintnell W, Yue D, Wehrli B, Jevnikar AM, Lee DM, Hueber W, Robinson WH, Cairns E: Arthritis induced by posttranslationally modified (citrullinated) fibrinogen in DR4IE transgenic mice. J Exp Med 2008, 205:967-979. 